\title{
A Research-based Teaching Model in ESL Reading Course at University Level: A Critical Thinking Perspective
}

\author{
Hai-Yan WANG* \\ Shanghai Jian Qiao University, No.1111, Huchenghuan Rd,Pudong,Shanghai 201306, P.R.China \\ *Email: sharedspace_why@163.com
}

Keywords: ESL reading comprehension context, Research-based Teaching model, Critical thinking, Teaching and learning strategies.

\begin{abstract}
Studies indicate that teachers with research-based teaching conceptions are more likely to implement practices involving students to think independently and critically. This thesis tries to make a theoretical study of the research-based teaching model to help foster students' critical thinking while reading in English. According to the author, three elements are important in facilitating this learning, namely, teaching philosophy, teachers and learning context. Specifically, this paper probes the important teaching and learning strategies in terms of teachers' behaviour. At the end of the article, a conclusion is made that learning outcome can be improved with adoption of a variety of teaching methods in reading course.
\end{abstract}

\section{Introduction}

Reading comprehension, the construction of meaning from text, is generally considered one of the most central cognitive skills students acquire during their school career [1]. For non-English majors, English reading courses provide the easy access to the acquisition of knowledge in different subject matters and constitute an important prerequisite for lifelong learning in adulthood [2].

The discussion of effective reading and the significance of using research-based practices for teaching reading continue to emerge in scholarly circles as topics of great concern in the educational arena today. In China, we find that most of the students have the problem with English reading. This is not a new concern or focus for Chinese education, however, this has been, and will be the focus for English teachers to meditate on how to prepare students with ways of reading. The interaction of text-based and knowledge-based processes is essential to reading comprehension, because the meaning of text is only partially determined by the text itself; reading must be an inferential constructive process [3]. Research-based teaching in reading is of extreme importance in fulfilling this process. Hopefully, research-based teaching is expected to be put into use in the teaching process to improve current situation.

The principle purpose of this thesis is trying to clarify what research-based teaching model is. Of equal importance is ascertaining whether and how the research-based teaching methods can be effectively implemented when the teachers are having lessons.

\section{Related Literature of Research-based Teaching Models}

Generally speaking, research-based teaching practice is illustrated in two aspects: teaching and learning. Based on research and observation, Daniels \& Bizar [4] have given the research-based teaching the following generally descriptive names: --reading as thinking, representing to learn, small-group activities, classroom workshop, authentic experiences, reflective assessment and integrative unit. Maier [5] maintains that students in a research-based teaching environment are taught by those who discover, create, apply and transmit knowledge and skills and are expected to engage with issues through questions that demand discussion, critical analysis, decision making and evaluation, mirroring a research approach that develops scholarship within the subject.

Brew [6] conceptualises the functions of research in learning and teaching in two ways: (1) Research-based learning that presents students with both the opportunity to conduct research and to 
develop research skills within their courses. (2)Research-enhanced teaching that emphasises the integration of a lecturer's research into the courses they teach.

But for college students whose developments are mostly fulfilled through acquiring knowledge, the "research" is still in a very preliminary stage. In order to make the research-based teaching methods plausible, we would like to refer to two important teaching and learning theories to support our idea before moving further to our new task.

One of the most important theories is Responsive Teaching theory (RTT), a type of instruction that utilizes small-group or individual instruction that promotes students' strategic decoding, comprehension, and response to text. In responsive teaching, teachers respond to what their students do at specific points. Teachers work with students before, during and after reading to discuss students' connections and responses to the text. During the discussion, teachers provide prompts and support to help students effectively construct meaning from their reading. With this theory as a guide, we can see teachers are playing a decisive role in instructing the students on how to get involved in a research-based learning context.

Another theory that works well is Reader Response theory (RRT), which focuses on the reader or audience reaction to a particular text, perhaps more than the text itself. This perspective argues that a text has no meaning before a reader reads-it. Students do not try to figure out the author's meaning as they read; instead, create a meaning that makes sense based on the text they are reading and on their background knowledge. This process is achieved by creating new ideas through text-totext, text-to-reader, and text-to-prior knowledge connections. This theory relates to this study in that learners should construct the meaning of texts in reading comprehension by playing an active and independent role.

\section{Fundamental Concerns in Research-based Teaching Model}

In this teaching model, three elements are taken into consideration: teaching philosophy, teachers and learning context. Both teachers and students are playing dynamic roles in the learning process, each having the responsibility to create a favourable leaning environment based on critical learning.

\section{Teaching Philosophy}

Teaching philosophy decides how the teacher will perform in a class and what outcome of the teaching might be expected. The ultimate purpose of research-based teaching is to cultivate students' skills and ability in independent thinking and problem solving. So to some extent, this process is more often related to teaching students' thinking. To be more specific, In terms of reading course, a research-based teaching and learning model takes place in an environment which can give full play to the students' learning initiatives that include the following:

Gather data and select data for reading\& learning

Understand meanings by interpreting, analysing, incorporating

Generate ideas by predicting, visualizing, inferring

Evaluate the work by reflecting and cooperating

With the research-based teaching, students are expected to develop the following abilities:

Question-generating and problems-solving

Independent thinking and judging

Active and collaborative learning

Self- regulating, self-managing and self-assessing

However, teaching thinking is never an isolated part, which is usually done in a separate period of time or in the form of a simple worksheet. It should be integrated into the whole learning process instead of being taken as a part after the lesson. In other words, thinking can take place anytime any place when the teacher wants them to, which is known as the conceptual-infusion approach. With this approach, thinking development is no longer conducted in a set of discrete procedures. On the contrary, it is infused into the curriculum, so that the students can apply the thinking ability to the situation naturally and automatically. Equally importantly, teachers are supposed to get the idea 
well across to the students that thinking is important and indispensable in reading so that both parties share the same value and work jointly towards that goal.

\section{Teachers’ Role}

Teachers must be well prepared to meet the diverse needs of students, this is particularly important in private colleges where the gap between the strong learner and weak learner is big in terms of their English reading skills. A qualified teacher should not just impart background knowledge or experiences, or simply explain word usage. In addition, he is supposed to teach about the causes and effects, relationships of roles, perspectives and reflections. In a research-based learning environment, teachers need to take the role of Assigning-Modelling-Monitoring-AssessingMentoring to make sure the whole process is totally provocative and students-centred.

Before lesson, teachers should focus on what needs to be done beforehand, making the instructions specific for the students to understand. This could provide very clear guidance and instructions for the students to follow in case they lack interest if the task is implicit or too much for them. In some cases, teachers need to demonstrate for the students to make the task easier.

Comprehensive monitoring is essential for reading, as it directs readers when trying to make sense of texts [7].The purpose of monitoring strategy is to train students to understand how well they are executing the reading skills and the efficiency of the reading process. By doing this, teachers foster the reader's awareness in their comprehension and employment of reading strategies and the students are reminded of evaluating their state of learning.

At the same time, teachers also provide feedback and immediate comment on the students' performance to ensure the reading outcomes, which can be stimulating and encouraging. In whatever way the assessment is done, the importance is to let the students feel reading itself is a rewarding and pleasant experience.

According to Ashburn, Mann and Purue [8], mentoring is the establishment of a personal relationship for the purpose of professional instruction and guidance. The teacher meets with the students on an as-needed basis (usually one-on-one instruction) to help the students with their selfreading activities and sort out the possible problem that may arise in the reading process. These teachers were concerned with the students by being responsive to the students' individual needs.

\section{Learning Context}

A favourable Learning context that facilitates research-based learning and thinking should be predictable enough for the learners to feel safe and think actively. Firstly, in this environment, students need to be respected and feel comfortable in communicating with others. Secondly, teachers and students need to share the viewpoint that thinking is essential, valued and enjoyable. Thirdly, the learning atmosphere created by the students in the learning process needs joint efforts from both parties. Once the students are all conducting good learning behaviours, a favourable learning environment will come into being. A favourable environment helps the students to increase their opportunities and willingness to use reading strategies to do the reading tasks. This also helps develop the students' autonomous learning and lifelong learning concept.

Students' learning behaviour includes participating, asking questions, listening to each other and offering help, which are very crucial in facilitating the natural and effective happening of the research-based teaching process. However, this learning behaviour only becomes a fixed pattern over a long period of tutoring and practicing. It might take years for students to learn handling paperwork, meeting the requirements and maintaining discipline. Teachers can challenge the students to use certain behaviours during the lesson; meanwhile, students can experience the challenge and pleasure of reading and thinking by practicing these behaviours on a regular basis.

\section{Research-based Teaching Practice}

Meaningful learning occurs when learners actively process the information they are asked to learn [9]. So in this circumstance, students can positively undertake the reading task and do the 
work as expected. In the following chapters, both teaching methods and reading strategies are discussed to ensure the best reading outcome.

\section{Research-based Teaching Methods}

In my previous teaching, the following active reading strategies turn out to be very effective ways to stimulate the students' motivation to do their own learning and display better outcomes than traditionally conducted reading classes.

Developing Metacognitive Awareness. Metacognitive awareness is considered as the key factor for proficient strategic reading since learners with metacognitive awareness could consciously direct the reasoning process and use strategies effectively. To make it more specific, I quoted some metacognitive awareness from İlknur Yüksel [10], the most important of which embraces the following:

1. Setting purpose for reading

3. Previewing text before reading

5. Guessing meaning of unknown words

7. Summarizing text information

9. Paraphrasing for better understanding

Obviously, the metacognitive awareness and strategies include both skills and disposition. Teachers should have a clear understanding of the concept and how to integrate it into their teaching. What's more, it takes a relatively longer time to get the students into a reading behaviour which consists of both. Once the students have the metacognitive strategies, they will be more interested in reading and become more self-regulated in doing the task. This development can be carried out in the following steps: The first step focuses on how to develop reading objectives and how to make a reading plan. The second step highlights raising awareness and developing specific strategies (which will be illustrated in details in the following chapter) related to the comprehension of the text. The third step emphasizes the importance of self-reflection and self-evaluation.

Collaborative-Learning Workshop. PALW has shown great promise as an effective supplement to conventional teaching methods to promote critical reading skills [11]. It is thought that students work best if engaged in groups rather than work individually. Students work in pairs consisting of a stronger and a weaker reader. Pairings can be decided by the teacher, who first rank-orders everyone in the class based on their reading performance. The teacher then divides the ranking in half and pairs the top student in the top half with the top student in the bottom half, and so on down the list. This way, the gap between the stronger and weaker reader in each pair is not too wide, and the teacher can select appropriate materials for each pair.

The teacher can implement all PALWS model with fidelity until he is proficient in understanding how all the components work together as designed. To make the collaborative learning more feasible, teachers may have it customized according to the learning environment and class performance. For example, students can be divided into groups of 3-4 students, each group consisting of similar level students with the top students as the leader or tutor.

What's more, teachers can engage students in medium-sized groups to share with each other what they have read, including their interpretation, feelings, thought and even perspectives. When a group has finished reading a selection, members may come together to raise questions about things they did not grasp, things they want to know more about, or issues they want to talk about. This process is of great importance, for it allows readers to discover that their interpretations may not be the only ones justified by the text.

Reading to Write. Traditionally, reading and writing are set as separate ways in promoting English skill, either through reading and writing courses or through different stages of a course. But studies find that reading-to-write is a useful model. The advantages of integrating reading with writing include the following steps: Reading to gain ideas about the topic; shaping opinion on the topic; using source texts for evidence, and using source texts for language support [12].

Reading-to-write gives the student an opportunity to select a writing topic from the source materials according to their own interest, which triggers curiosity and leaves thinking space to 
individuals [13]. This reading-to-write method, like input-and output process, allows the students to make full use of the given information to create something new based on their own understanding. For students to write well, aesthetic reading can be adopted, which is a manner of reading where the reader's attention is primarily focused on the experience, feelings, attitudes, and ideas that the text arouses. Generally, reading involves the writer's attitude, feelings and opinions; therefore, reading is not just a passive reception of the information, but an interaction between readers and the text materials. With the aesthetic reading method, students will step back to read the text and figure out what the author is trying to get across to the reader. This might also help throw some light on how to form a different perspective in writing.

This process can be perfected through summary writing, simulated writing, and critical writing to creative writing. Simulated writing is mostly done on the basis of the targeted reading text, using the given ideas and words and expression; while critical writing and creative writing involves one's own understanding of a different perspective. It is clear that reading-to-write helps the learners to shift from two previous attitudes: shift from the passive reception of knowledge to an active seeking for knowledge; shift from the rote-learning of the text to a practical use of the knowledge [13].

Fostering Critical Thinking. Critical thinking involves one or more of the following abilities: identifying assumptions and arguments; recognizing important relationships; evaluating evidence; deriving inferences from available information; and evaluating the validity of conclusions [14]. Motivating students to embark on a journey of critical thinking and reflection can be challenging.

Comprehension beyond the word level requires the reader not only to activate background knowledge, but also use it in integrating meaning across sentences. Many poor readers have difficulty in inferring the target reading, which actually is very important to activate students' critical thinking. If the students have difficult in independent thinking, teachers need to give some enlightenment by inviting questions to guide the students. But it should be noted that the questions should be broader and subjective, for example, sometimes they can be set as open-ended questions, in case they should limit the students' thinking. Examples of how to invite questions may give a teacher, as is shown in Table 1:

Table 1. Examples of how to invite questions

\begin{tabular}{|c|c|}
\hline Procedures & Questions \\
\hline Relating & $\begin{array}{c}\text { Do you notice the transfer of tenses? } \\
\end{array}$ \\
\hline Inferring & Woes it make sense to get the two paragraphs inversed? \\
\hline Predicating & What can you get between the lines? \\
\hline Summarizing & What will come next? \\
& What is going to happen? \\
\hline Self-assessing & Are there any cohesive device used? \\
& Can you picture it in your mind? \\
\hline Did you reread to see if you are correct? \\
What other ways can be suggested?
\end{tabular}

To make the procedures in Table. 1 possible, a teacher needs to make a full preparation for what is going to be taught, and this preparation is more often in the form of active thinking as well, through intellectualizing, question designing and reflecting rather than simply materials collecting, delivering or lecturing.

\section{Research-Based Reading Strategies}

It is important to note that reading presents a gap between the writer and the reader. To fill this gap, readers need the necessary skills and strategies to be able to cope with any kind of reading text and bridge this gap. Basically, in order to understand well, students need vocabulary, knowledge of grammar and background information. But to go beyond the information given by the text, students need to grasp a set of more complex abilities including predicating, analysing, guessing, inferring, evaluating, comparing, incorporating and synthesizing, which are all extremely crucial to the development of critical thinking. Here I present the reading comprehension strategies based on the 
above-mentioned teaching methodology. These theories assisted me in exploring the research-based strategies that worked well in my previous teaching.

Generating Questions. The strategy for self-questioning is the first step in reading, which is very helpful for the readers to be more focused on the reading texts. Learners ask themselves questions regarding who, what, where, when and why; for expository texts, what, how, why and relationships are more important; while for argumentation, readers need to put more emphasis on what is being discussed, perspectives and supporting details. These mini-tasks prior to reading can not only enhance concentration, also facilitate comprehension. Question generation encourages learners to be actively and independently involved and to become aware of whether they understand texts or not and, thus improves comprehension ability [15]. By openly questioning our own ideas and assumptions-even as we explain why we believe in them so passionately-we create an emotional climate in which accepting change and risking failure are valued [16]. By generating further questions, students should be able to put forward their own opinions about the problem, predicate what is happening next, generate their own ideas or even create something new.

Activating Schema. A schema is a hypothetical mental structure for representing generic concepts stored in memory [3]. Schemata include prior knowledge in a form of frame work or background knowledge, which help readers expect or predict in their interpretation of a text. Schemata are considered to be necessary for regulating and organizing the reader's reading experience and his ability to interpret the meaning of the text. The degree to which the meaning and the structure of a text is made apparent to the reader depends largely on whether the selected schemata are consistent with the text. This is very helpful in assisting the students to bridge the gap between the prior knowledge and unknown information.

Previewing, a good way to activate the scheme, occurs prior to the class, involving connection to background knowledge as well as predictions of the reading materials. But if the prior knowledge is inaccessible, readers may be unable to create new structure based on the present information and new concept. For those low-levelled students, a schema may be difficult to form, in which case, teachers may help connecting between the old knowledge and new knowledge either by prompting background information, identifying the cues of reading material or collecting shared knowledge. The more students know about the text, the less likely they feel limited in interpreting the text. Reading is an interactive process, so readers may vary quite differently in terms of the interpretation in order to make sense of the text, largely because of prior knowledge imposed on the text and subjunctive approaches in the text.

Embedding Graphic Organisers. It is often assumed that college English reading is mainly concerned with the identification of new words with the purpose of figuring out the unknown concepts or difficult sentences. However, reading is not just to identify the new words and difficult sentences. Rather, students need to take the passage as a whole in order to get the main idea and extract some valuable information or even make possible inference and analysis by getting a thorough the reading materials.

Graphic organizer, also called concept mapping, is a very effective way to get the reading information simplified and organized. They help to view text as a sequence of relationships from one paragraph to the next rather than separate the whole passage into segments. When teaching materials are presented through concept maps, students could easily find the interrelation of the concepts. It is generally believed that any passage can fit in a certain graphic pattern in accordance to the writing style, writing strategies and thinking pattern, because each passage should be constructed in a logical and organised way. To avoid the difficulty regarding the learners' reading level, the teacher may adopt the concept map blank-filling strategy, asking students to select the corresponding important messages and information to the missing parts of the concept maps. Sometimes we can also ask the students to create their own based on their own understanding of the whole passage. But before that, teachers may give a model for the students to follow. In teaching the use of graphic organisers, teachers must ask learners to construct an image that represents the content. These graphic organisers can help create visual image for the students to understand the text better. Examples of the graphic mappings are illustrated in Fig 1: 

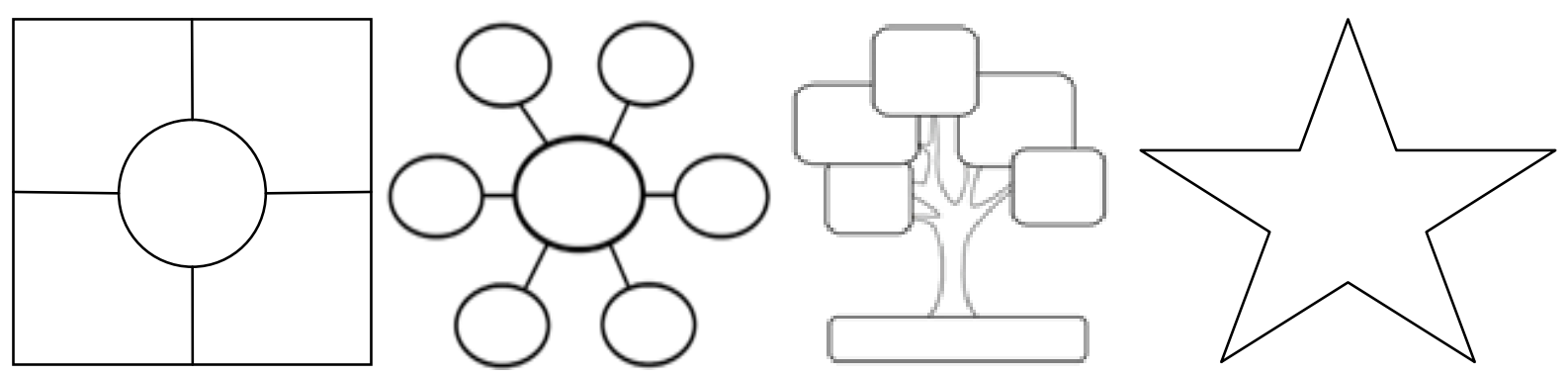

Figure 1. Examples of graphic mappings

Reconstructing the Passage. A passage structure may be made clear under the guidance of the teacher, by referring to the key words and expression, topic sentences, transitional device, transfer of tense, cohesive words, semantic organizers, etc. If the students are familiar with the structure and some of the key words meanings of each paragraph and segment, they may be better able to reconstruct the whole passage either using their own words and expressions or the words picked up in reading the passage in a clear and coherent manner; and in turn, the reconstruction will certainly enhance further understanding of the reading material and application of the learned words and expressions. This can be done in a form of summarizing or retelling, a process of sorting out important information and condense information. This process is a strategy that helps students to foster further understanding on a basis of summarizing the text. However, for students who are doing poorly in English reading, summarizing can be difficult to carry out. Teachers need to let the students to practice more before applying this kind of method and tell the students what to do and how to do it. But, generally speaking, this is very helpful in facilitating better access to the text on the whole rather than take it apart. This reading strategy can also be applied to group leaning and reading, in which process, students get mutually benefited by sharing views and ideas.

\section{Conclusions}

A set of teaching and reading strategies have been discussed, which, to be objective, are not applicable in every situation. On the one hand, there exist problems with those students who are not doing well in English reading and who lack self-discipline. For this reason, cooperation can be difficult to carry out. On the other, selecting appropriate reading materials is extremely difficult. When working with a classroom of fifty students, it is impossible to choose texts that fit everyone.

In spite of the limitations, some important ideas are notable and call for further research. This study provides information about how teaching methods are conducted in classrooms. In addition, the study reveals a possibility for further investigation into broader aspects of implementation of research-based teaching in reading course. Several aspects, like assessment and strategies, can be further explored and addressed in details on how to make sure the purpose of research-based teaching is fully fulfilled.

With the improvement of teaching methods, it is hoped that students could benefit from active learning and independent thinking. First of all, students can develop an interest in reading and autonomous reading; secondly, students may greatly improve their learning efficiency with more reading strategies involved; thirdly, through reading, they not only acquire knowledge but also think independently.

\section{Acknowledgements}

This research was funded by Shanghai Jian Qiao University, the project number being JXGG140322.

The accomplishment of this thesis should be owned to my respected supervisor, Anita Jetnikoff, who has spent much time and effort on her generous provision of constructive suggestions. I also express my gratitude to all the other teachers in QUT for their constructive advice. 


\section{References}

[1] L. H. Mason, Explicit self-regulated strategy development versus reciprocal questioning: effects on expository reading comprehension among struggling readers. Journal of Educational Psychology, 96 (2004) 283-296.

[2] D. E. Alvermann, J. Earle, Comprehension Instruction. In A. P. Sweet \& C. Snow (Eds.), Rethinking reading comprehension, Guilford, New York, 2003, pp. 12-30.

[3] S. Ibrahim, Abu, Reading as critical thinking, Asian Social Science, Canadian Centre of Science and Education, Vol.7, No.8 (2011) 209.

[4] H. Daniels, M. Bizar, Teaching the best practice way: Methods that matter, K-12. ME: Stenhouse, Portland, 2005.

[5] P. Maier, Defining and identifying research-led teaching. Retrieved on http:// www.clt.soton.ac.uk/ (2006).

[6] A. Brew, Imperatives and challenges in integrating teaching and research, Higher Education Research and Development, Vol. 29, No. 2 (2010)139-50.

[7] R. Routman, Conversations: Strategies for Teaching, Leaning and Evaluation. Heinemann, Portsmouth, 2000.

[8] C. Asburn, M. Mann, P. A. Purdue, Teaching mentoring: ERIC Clearinghouse on teaching education. Submitted to American Education Research Association (1987).

[9] M. Ndileleni Paulinah, Research-based teaching comprehension strategies: Bridging the Gap, Journal of Language Teaching and Research, Vol. 4, No. 2 ( 2013) 317-327.

[10] Y. İlknur, Y. İsmail, Metacognitive awareness of academic reading strategies. ProcediaSocial and Behavioral Sciences, 31(2012) 894-898.

[11] L. Kristen, McMaster. Promises and limitations of peer-assisted learning strategies in reading learning disabilities, A Contemporary Journal, 5 (2007) 97-112.

[12] L. Plakans, A. Gebrial, Using multiple texts in an integrated writing assessment: Source text use as a predictor of score, Journal of Second Language Writing, 22(2013)217-230.

[13] Zhan-fang Li, Chun-hong Yang, Reading-to-write: A practice of critical thinking, Journal of Arts and Humanities, Volume 3, No. 5(2014)

[14] E. Pascarella, P. Terenzini, How College Affects Students: Findings and Insights from Twenty Years of Research, Jossey-Bass Publishers, San Francisco, 1991

[15] N. K. Duke, P.D. Pearson, Effective Practices for Developing Reading Comprehension. In A.E. Farstup \& S.J. Samuels (Eds.), What Research has to Say about Reading Instruction, third ed., International Reading Association, Newark, (2002) 205-242.

[16] S D. Brookfield, Becoming a Critically Reflective Teacher. Jossey-Bass Publishers, San Francisco, 1995. 